\title{
Antihistamine Use in Early Pregnancy and Risk of Birth Defects
}

\author{
Qian Li, MS ${ }^{1}$, Allen A. Mitchell, MD², Martha M. Werler, ScD ${ }^{2}$, Wai-Ping Yau, PhD $^{1,3}$, and \\ Sonia Hernández-Díaz, MD, DrPH ${ }^{1}$ \\ ${ }^{1}$ Department of Epidemiology, Harvard School of Public Health, Boston, MA, United States \\ 2 Slone Epidemiology Center at Boston University, Boston, MA, United States \\ ${ }^{3}$ Department of Pharmacy, National University of Singapore, Singapore
}

\begin{abstract}
Background-Several studies have reported an association between use of specific antihistamines in early pregnancy and certain specific birth defects.

Objective-To test 16 previously-hypothesized associations between specific antihistamines and specific birth defects, and identify possible new associations.

Methods-We used 1998-2010 data from the Slone Epidemiology Center Birth Defects Study, a multicenter case-control surveillance program of birth defects in North America. Mothers were interviewed within six months of delivery about demographic, reproductive, medical, and behavioral factors, and details on use of prescription and non-prescription medications. We compared $1^{\text {st }}$ trimester exposure to specific antihistamines between 13,213 infants with specific malformations and 6,982 non-malformed controls, using conditional logistic regression to estimate odds ratios (ORs) and 95\% confidence intervals (CIs), with adjustment for potential confounders, including indication for use.
\end{abstract}

Results-Overall, $13.7 \%$ of controls were exposed to antihistamines during the $1^{\text {st }}$ trimester. The most commonly-used medications were diphenhydramine (4.2\%), loratadine (3.1\%), doxylamine (1.9\%), and chlorpheniramine (1.7\%). Where estimates were stable, none supported the previously-hypothesized associations. Among over 100 exploratory comparisons of other specific antihistamine/defect pairs, 14 had ORs $\geq 1.5$ of which 6 had 95\% CI bounds excluding 1.0 before but not after adjustment for multiple comparisons.

Conclusion-Our findings do not provide meaningful support for previously-posited associations between antihistamines and major congenital anomalies; at the same time, we

\footnotetext{
Corresponding author: Allen A. Mitchell, M.D. Slone Epidemiology Center, 1010 Commonwealth Ave. Boston, MA 02215 Phone: 617734 6006; Fax: 617738 4119; allenmit@bu.edu.

Conflict of interest disclosure:

The Pharmacoepidemiology Program at the Harvard School of Public Health is partially supported by training grants from Pfizer, Millennium and Asisa. The Slone Birth Defects Study receives support from a number of pharmaceutical manufacturers that may make products included in this study, but this analysis was not supported by commercial entities nor were they aware of it. Dr. Mitchell consulted on one occasion for Duchesnay, the manufacturer of Diclegis; while this product was not the subject of this analysis, one of its ingredients (doxylamine) was. Dr. Mitchell serves as a consultant to Biogen-Idec in his role as a member of the Tysabri Pregnancy Registry Advisory Committee. Dr. Hernández-Díaz has consulted for Novartis, AstraZeneca, and GSK_Biologics. Dr. Werler is on advisory boards of manufacturer-sponsored studies that evaluate pregnancy outcomes among women treated with medications for rheumatoid arthritis; No known conflict is identified. Ms.Li and Dr. Yau have no conflict of interest to report.
} 
identified associations that had not been previously suggested. We suspect that previous associations may be chance findings in the context of multiple comparisons, a situation which may also apply to our new findings.

\section{Keywords}

Antihistamines; birth defects; first trimester; maternal exposure

\section{INTRODUCTION}

Antihistamines are used for the symptomatic treatment of allergic rhinitis as well as the treatment of nausea and vomiting, motion sickness, dizziness, and insomnia. ${ }^{1}$

Antihistamines are among the most commonly-used drugs during pregnancy, ${ }^{2}$ and most are considered FDA category B (no evidence of human risk after in utero exposure) due to the scarce number of controlled studies in pregnant women. ${ }^{3}$ Given their wide use and availability without prescription ("over-the-counter", or OTC), even a small increase in the risk of specific birth defects may have considerable clinical and public health implications. On the other hand, if these medications are relatively safe, such information is important to diminish unwarranted fears of fetal damage secondary to exposure.

Epidemiologic studies that have examined antihistamines in the aggregate and birth defects overall are uninformative because of varied pharmacologic actions within the class of antihistamines and varied etiologies across the range of birth defects. ${ }^{4}$ Most studies that have considered specific drugs in relation to specific defects have generally identified no associations between maternal use of antihistamines and major birth defects. ${ }^{5-24}$ However, positive associations have been reported for diphenhydramine in relation to cleft palate, ${ }^{25}$ cleft lip with or without cleft palate, neural tube defects, spina bifida, limb reduction defects, and gastroschisis $;{ }^{26}$ loratadine in relation to hypospadias; $; 2,28$ chlorpheniramine in relation to eye defects, ear defects, ${ }^{29}$ spina bifida, and cleft lip with or without cleft palate; ${ }^{26}$ doxylamine in relation to oral clefts, ${ }^{30}$ pyloric stenosis, ${ }^{31,32}$ hypoplastic left heart syndrome, spina bifida, and neural tube defects. ${ }^{26}$

Using data from the Slone Epidemiology Center Birth Defects Study (BDS—also known as the Pregnancy Health Interview Study), we tested the previously-reported associations between specific birth defects and first trimester exposure to antihistamines and explored whether there might be associations between specific antihistamines and other common specific major congenital malformations.

\section{METHODS}

\section{Study population}

The BDS is an ongoing multicenter case-control surveillance program of birth defects in North America; details have been described elsewhere. ${ }^{33-35}$ Malformed infants/fetuses were identified as potential cases at regional centers around Boston (1976-present), Philadelphia (1977-present), Toronto (1979-2006), and San Diego (2001-present), and from birth defects registries in Massachusetts (1998-present) and New York State (2004-present); non- 
malformed infants were identified as potential controls at participating hospitals (1993present) and from a population-based sample of non-malformed infants in Massachusetts (1998-present). The present analysis was based on data from subjects interviewed between 1998 and 2010. After exclusion of mothers who were ineligible and could not be contacted and invited to participate, the participation rate was $73 \%$ for mothers of cases and $68 \%$ for mothers of controls. ${ }^{36}$ Oral informed consent was obtained from mothers, and the study has been approved by the Institutional Review Boards of all relevant institutions, and is fully compliant with requirements of the Health Insurance Portability and Accountability Act.

\section{Cases and controls}

Cases consisted of infants and fetuses with confirmed diagnoses of isolated or multiple major congenital malformations. Only categories with defects containing more than 100 cases were considered; these included neural tube defects, spina bifida, eye defects, ear defects, oral clefts, cleft lip with or without cleft palate, cleft palate, tracheo-esophageal fistula, pyloric stenosis, small intestinal atresia/stenosis, anal atresia/stenosis, intestinal malrotation, clubfoot, limb reduction defects, gastroschisis, diaphragmatic hernia, renal agenesis/dysgenesis, cystic kidney disease, renal collecting system defects, extra or horseshoe kidney, undescended testis, hypospadias, conotruncal defects, tetralogy of Fallot, d-transposition of great arteries, aortic arch anomalies, ventricular septal defect, atrial septal defect, right ventricular outflow obstruction, pulmonary valve stenosis/atresia, left ventricular outflow obstruction, coarctation of aorta, hypolastic left heart syndrome, and great veins anomalies. Major malformations are confirmed by the physicians of study subjects and by the mothers during interview; for subjects who provide medical record releases, diagnoses are also validated via medical record review. We excluded infants with chromosomal defects, known Mendelian inherited disorders, syndromes, DiGeorge sequence, and amniotic bands, under the assumption that their etiologies are unlikely to be caused by antenatal exposures. Cases with more than one anomaly were considered in each defect category.

Our primary controls were non-malformed infants enrolled in BDS during the same time period. To address possible concerns about recall bias, we conducted sensitivity analyses in which cases with a specific birth defect were compared to a secondary control group consisting of infants with all other structural malformations (including those with $<100$ subjects).

\section{Exposure ascertainment and classification}

Study nurses conducted standardized phone interviews of mothers within 6 months of delivery, with neither the nurses nor mothers aware of the various study hypotheses. Questions include maternal demographic, anthropometric, reproductive, medical, and lifestyle characteristics. Information is also obtained on all medications (prescription, OTC, vitamins and minerals, and herbal products) used at any time from 2 months before the last menstrual period (LMP) until the end of pregnancy. Medication-related questions are asked in a multilevel approach. First, women are asked whether they experienced any of a list of specific illnesses (e.g., allergies) during pregnancy and the drugs they may have used to treat those conditions. Then they are asked about their use of categories of medications (e.g., 
antihistamines), and finally about use of specific medications, including brand and generic names. Mothers who reported taking a medication were asked to identify the dates when use began and ended; recall was enhanced by a calendar highlighting key dates and events (e.g., LMP, Christmas, delivery date).

We studied the two generations of antihistamines, whether available by prescription or OTC - the older sedating products (e.g., chlorpheniramine, diphenhydramine, dimenhydrinate, doxylamine, promethazine), and the newer non-sedating products (e.g., loratadine, cetirizine, fexofenadine). For the timing of gestational exposure, the LMP date was determined by early ultrasound examination or maternal recall. We defined the estimated date of conception (i.e., day 0) as 14 days after the LMP date, and the first trimester of pregnancy as days 0-89. We considered "exposed" as maternal use of the antihistamine on at least one day during the first trimester. Using a previously-developed exposure classification algorithm that considers recall uncertainty in reported timing of medication exposure, ${ }^{37}$ we classified antihistamines exposure in the first trimester into 'likely exposed' and 'possibly exposed'. While secular trend analyses used both definitions, etiologic comparisons compared only 'likely exposed' women to women without any use of the medication from 2 months before conception throughout delivery (i.e., reference group).

\section{Statistical analyses}

We first characterized the trends of utilization patterns for specific antihistamines over time as well as by trimesters. To understand the risk factors associated with antenatal exposure to antihistamines, among controls we compared first trimester-exposed women with unexposed women according to sociodemographic and life-style characteristics, prevalence of selected co-morbidities and the medications used concomitantly. Finally, we evaluated the associations between first-trimester exposure to specific antihistamines in relation to 1) the risk of specific malformations previously hypothesized to be associated with each of these drugs, and 2) in exploratory analyses, the risk of other relatively common malformations. To obtain stable estimates, we only evaluated the most commonly-used antihistamines in our population and considered only malformations with $\geq 100$ cases; in the exploratory analyses, we restricted consideration to cells with $\geq 5$ exposed cases. Conditional logistic regression was used to estimate odds ratios (ORs) and 95\% confidence intervals (CIs) for specific malformations associated with first-trimester exposure to each antihistamine. We matched controls to cases by stratifying on estimated conception year and study region and adjusted for potential confounders by including terms in multivariable models. In the exploratory analyses we adjusted for multiple comparisons using Bonferroni ${ }^{38}$ and BenjaminiHochberg ${ }^{39}$ approaches. For any positive associations found in the exploratory analyses, we assessed potential recall bias by conducting sensitivity analyses using our secondary control series (i.e., other malformed infants). To account for etiologic heterogeneity and provide analyses comparable to those conducted in the U.S. National Birth Defects Prevention Study, ${ }^{26}$ in secondary analyses we restricted cases to those with isolated defects. 


\section{RESULTS}

\section{Utilization patterns of antihistamines in pregnancy}

Between 1998 and 2010, our study population included 13,213 infants with malformations and 6,982 non-malformed controls. Overall, $14.9 \%$ of cases and $13.7 \%$ of controls were exposed to antihistamines during first trimester. Among controls, the most commonly-used antihistamines were diphenhydramine (4.2\%), loratadine (3.1\%), doxylamine (1.9\%), and chlorpheniramine (1.7\%); the most common indications for antihistamine medications were allergy, followed by nausea/vomiting, cold/flu, and insomnia. The prevalence of antihistamine use decreased from early to late pregnancy, except for diphenhydramine, where use slightly increased from $4.2 \%$ in the first trimester to $5.1 \%$ in the third trimester.

Secular patterns for first-trimester use, based on data from the Boston and Philadelphia study sites which have been participating in the BDS throughout the study period (Figure 1), revealed that diphenhydramine use has been increasing, making it the most commonly-used antihistamine, reaching a prevalence of $6.4 \%$ by 2009 . Use of loratadine also increased appreciably, to almost $5 \%$ in the late 2000s. On the other hand, chlorpheniramine use has decreased over the years and was most recently reported by only $1 \%$ of women. Use of antihistamine medications not shown in Figure 1 was not appreciable.

\section{Characteristics of first trimester antihistamine users}

Among controls, factors associated with first trimester use of antihistamines included older maternal age, white race/ethnicity, higher pre-pregnancy body mass index, higher education level and income, and alcohol and coffee drinking (Table 1). As expected, first trimester antihistamine use was related to conditions that are indications for antihistamine medications, which included allergy, asthma, nausea/vomiting, sleeping problems, respiratory infection and cold/flu. Medications associated with first trimester antihistamine use included oral corticosteroids, decongestants, acetaminophen, aspirin, non-steroidal antiinflammatory drugs, and antibiotics. All these factors were considered as potential confounders in subsequent analyses.

\section{Risk of major malformations associated with first trimester antihistamine use}

The 16 previously-hypothesized associations between specific major malformations and use of specific antihistamines were confined to the four most commonly-used agents diphenhydramine, loratadine, chlorpheniramine, and doxylamine. As reflected in Table 2, none of these associations had lower 95\% CIs that excluded 1.0. However, some of the estimates were based on small numbers and the $95 \%$ CIs were very wide. For example, use of chlorpheniramine in relation to ear defects and spina bifida showed positive associations based on only 3 and 4 exposed cases, respectively. However, where cells included at least 5 exposed cases, none had adjusted estimates with upper CIs that exceeded 3.0.

In exploratory analyses involving a total of 107 comparisons, six exposure-outcome pairs had elevated ORs with lower 95\% CI bounds exceeding 1.0 (Table 3): diphenhydramine and D-transposition of great arteries (OR: 2.3, 1.1-5.0); doxylamine and cystic kidney disease (OR: 2.7, 1.3-5.6); and chlorpheniramine and neural tube defects (OR: 2.6, 1.1-6.1), 
tetralogy of Fallot (OR: 3.1, 1.2-8.4), hypoplastic left heart syndrome (OR: 4.9, 1.6-14.9), and great veins anomalies (OR: 3.3, 1.1-10.0). Loratadine use was inversely associated with oral clefts (OR: 0.5, 0.3-0.9). Another 8 exposure-outcome ORs were $\geq 1.5$ but $95 \%$ CIs were wide and included 1.0. In the sensitivity analyses using secondary malformed controls in each comparison, the OR estimates generally changed little (see Table E1 in the Online Repository). However, all CIs included 1.0 after adjustment for multiple comparisons using Bonferroni or Benjamini-Hochberg approaches. Secondary analyses restricted to cases with isolated defects did not reveal meaningful changes in the above findings (data not shown).

\section{DISCUSSION}

The findings from our study did not replicate any of the 16 previously-reported associations between specific antihistamines and major congenital malformations. Many of the previous studies involved multiple comparisons and small numbers of cases. Therefore, we posit that many if not all of these hypothesized associations could be explained by chance. On the other hand, in our exploratory analyses that involved 107 comparisons, we identified 14 associations that had ORs $\geq 1.5$ of which 6 had 95\% CI bounds excluding 1.0; these 6 associations either had not been previously reported or were reported as null. ${ }^{26}$ All the CIs included 1.0 when we employed two widely-used multiple-comparison adjustment approaches, supporting the possibility of false positive associations. Further, by restricting the exploratory analyses to cases with at least 5 exposed subjects, among the case groups with small numbers we are selecting those with higher prevalence of exposure and therefore preferentially identifying positive associations. Thus, findings from our exploratory analyses should be considered only to have generated hypotheses.

In the early 1980s, many lawsuits alleged that Bendectin, which included the antihistamine doxylamine along with vitamin B6, caused birth defects, leading its manufacturer to voluntarily withdraw it from the market in $1983 .{ }^{40}$ As Figure 1 reveals, the prevalence of doxylamine use in pregnant women was quite low during the period of our study. Extensive studies of Bendectin, including two of our own, found no evidence to support earlier concerns, and in fact established the relative safety of this medication. ${ }^{33,41,42}$ Our current findings provide additional evidence supporting the relative safety of doxylamine. Of note, in April 2013, the U.S. FDA approved Diclegis, having the same ingredients as Bendectin, for treating nausea and vomiting in pregnant women. ${ }^{43}$

Werler et al previously described trends of diphenhydramine, loratadine, doxylamine, and chorpheniramine use among women in the BDS through $2004 .^{2}$ In the present analysis, the previously-reported increases in use of diphenhydramine and loratadine appeared to continue to 2009, while use of doxylamine remained infrequent and use of chlorpheniramine continued to decrease.

We did not have sufficient power to provide stable risk estimates for the previouslyhypothesized association of chlorpheniramine and ear defects, but a 3-fold risk was observed. For the hypothesized association between chlorpheniramine and spina bifida, the OR was 1.7 (0.6-5.3), and in the exploratory analyses, we observed an elevated risk for any neural tube defects (OR: 2.6, 1.1-6.1), due to a very large but unstable risk for encephalocele 
(OR: 20.4, 2.5-166.2). We also found 3 additional positive associations with ORs $>3$ in the exploratory analyses for chlorpheniramine. However, for reasons noted above, these findings should be interpreted with caution.

Our study has several strengths. First, BDS contains comprehensive information on OTC drug use in contrast to datasets that are largely limited to prescription drugs. In addition, the interview-based data collection obtains critical covariates such as maternal reproductive history, smoking, alcohol, periconceptional folate and multivitamin use, and treatment indications. These variables are rarely directly available in administrative databases, and it is of particular value that the BDS included information on important potential confounders. Second, we gave special consideration to reducing potential biases in our study design and analysis; these included detailed and structured data collection, outcome validation, comparisons involving both nonmalformed and malformed control groups, and conducting multivariate adjustment and sensitivity/secondary analyses.

On the other hand, there were several limitations in our study. First, despite the large number of subjects, we had sufficient power only to evaluate associations between the most common antihistamine medications and relatively common malformations. Capacity to examine the potential dose-effect (dose or days of exposure) was limited. Second, our data were collected retrospectively by maternal reporting. Although many approaches are in place to improve the accuracy of maternal recall and reporting in the BDS, recall bias ${ }^{44,45}$ and exposure misclassification remain possible. With respect to recall bias, the mother of a normal infant may search her memory less thoroughly than the mother of a malformed infant, and thus might underreport antenatal exposures, which would lead to an overestimation of the true risk. Because recall bias is unlikely to be defect-specific, our use of malformed infants as a secondary control group maximized the likelihood of symmetrical recall in cases and controls. Sensitivity analyses involving malformed controls yielded similar elevations in risk, reducing the likelihood that recall bias accounts for positive findings. With regard to exposure misclassification, the detailed information about medication use collected by the BDS allowed us to create separate categories of subjects who varied in their likelihood of exposure. By restricting our definition of exposure to only those women considered most likely to have been exposed, we sought to minimize exposure misclassification. Third, although we considered specific malformations rather than defects by organ system or birth defects overall, there might still be etiologic heterogeneity within some specific case groups where inclusion of diverse subtypes is likely ${ }^{46,47}$ or when cases with isolated or multiple defects were considered together. However, when we restricted the analyses to cases with isolated defects only, findings did not materially change.

We suspect that many if not all previously reported associations between antihistamines and birth defects may be chance findings observed in the context of multiple comparisons, a situation which may also apply to the findings in the current study. Therefore, it is important that others test the hypotheses generated from our exploratory analyses. In conclusion, accumulated epidemiological evidence does not provide meaningful support for any strong associations between common specific antihistamines and major congenital malformations. 


\section{Supplementary Material}

Refer to Web version on PubMed Central for supplementary material.

\section{Acknowledgments}

We want to thank Dawn Jacobs, RN, MPH, Fiona Rice, MPH, Rita Krolak, RN, Kathleen Sheehan, RN, Moira Quinn, RN, Clare Coughlin, RN, Nancy Rodriquez-Sheridan, Carolina Meyers, Joan Shander, and Paula Wilder for their assistance in data collection; Nastia Dynkin for computer programming; the staff of the Massachusetts Department of Public Health Center for Birth Defects Research and Prevention, Dr Charlotte Druschel and the New York State Health Department, and Drs Christina Chambers and Kenneth Jones of the University of California, San Diego, as well as the medical and nursing staff at all participating hospitals for assistance with case ascertainment: Baystate Medical Center, Beth Israel Deaconess Medical Center, Boston Medical Center, Brigham and Women's Hospital, Brockton Hospital, Cambridge Hospital, Caritas Good Samaritan Medical Center, Charlton Memorial Hospital, Children's Hospital, Emerson Hospital, Falmouth Hospital, Haverhill-Hale Hospital, Jordan Hospital, Kent Hospital, Lawrence General Hospital, Lowell General Hospital, Melrose-Wakefield Hospital, Metro West Medical Center-Framingham, Mt Auburn Hospital, New England Medical Center, Newton-Wellesley Hospital, North Shore Medical Center, Rhode Island Hospital, Saints Memorial Medical Center, South Shore Hospital, Southern New Hampshire Medical Center, St Elizabeth's Medical Center, St Luke's Hospital, St Vincent Hospital, UMASS Memorial Health Care, Women and Infants' Hospital, Abington Memorial Hospital, Albert Einstein Medical Center, Alfred I. duPont Hospital for Children, Bryn Mawr Hospital, Chester County Hospital, Children's Hospital of Philadelphia and their Clinical and Translational Research Center, Christiana Care Health Services, Community Hospital, Crozer-Chester Medical Center, Doylestown Hospital, Frankford Hospital, Hahnemann University Hospital, the Hospital of the University of Pennsylvania, Lankenau Hospital, Lancaster General Hospital, Lehigh Valley Hospital, Nanticoke Memorial Hospital, Pennsylvania Hospital, Sacred Heart Hospital, St Christopher's Hospital for Children, St Mary Medical Center, Temple University Health Sciences Center, Reading Hospital and Medical Center, Thomas Jefferson University Hospital, Grand River Hospital, Guelph General Hospital, Hamilton Health Sciences Corp, the Hospital for Sick Children, Humber River Regional Hospital-Church Site, Humber River Regional Hospital-Finch Site, Joseph Brant Memorial Hospital, Lakeridge Health Corp, London Health Sciences Center, Mt Sinai Hospital, North York General Hospital, Oakville Trafalgar Memorial Hospital, Scarborough Hospital_General Division, Scarborough Hospital_Grace Division, St Joseph's Health Center-London, St Joseph's Health Center-Toronto, St Joseph's Healthcare-Hamilton, St Michael's Hospital, Sunnybrook and Women's College Health Sciences Center, Toronto East General Hospital, Toronto General Hospital, Trillium Health Center, William Osler Health Center, York Central Hospital, York County Hospital, Alvarado Hospital, Balboa Naval Medical Center, Camp Pendleton Naval Hospital, Children's Hospital and Health Center, Kaiser Zion Medical Center, Palomar Medical Center, Pomerado Hospital, Scripps Mercy Hospital, Scripps Memorial Hospital-Chula Vista, Scripps Memorial Hospital-Encinitas, Scripps Memorial Hospital-La Jolla, Sharp Chula Vista Hospital, Sharp Coronado Hospital, Sharp Grossmont Hospital, Sharp Mary Birch Hospital, Tri-City Medical Center, and University of California, San Diego Medical Center; we particularly thank all the mothers who participated in the study.

Sources of financial support:

This study was supported by grant R01 HD046595-04 from the Eunice Kennedy Shriver National Institute of Child Health and Human Development (NICHD).

\section{Abbreviations}

OTC over-the-counter

BDS Birth Defects Study

LMP last menstrual period

OR odds ratio

CI confidence interval

BMI body mass index

NSAID non-steroidal anti-inflammatory drug 


\section{REFERENCES}

1. Hardman, JG.; Limbird, LE.; Goodman-Gilman, A. Goodman \& Gilman's The pharmacological basis of therapeutics. tenth ed.. McGraw-Hill; New York: 2001.

2. Werler MM, Mitchell AA, Hernandez-Diaz S, Honein MA. Use of over-the-counter medications during pregnancy. Am J Obstet Gynecol. Sep; 2005 193(3 Pt 1):771-7. [PubMed: 16150273]

3. Briggs, GG.; Freeman, RK.; Yaffe, SJ. Drugs in pregnancy and lactation. 7th ed.. Lippincott Williams \& Wilkins; Philadelphia: 2002.

4. Mitchell, AA. Studies of Drug-Induced Birth Defects, in Pharmacoepidemiology, Fifth Edition. Strom, BL., editor. John Wiley \& Sons, Ltd; Chichester, UK: 2012.

5. Aselton P, Jick H, Mulunsky A, Hunter J, Stergacjis A. First-Trimester drug use and congenital disorders. Obstet Gynecol. 1985; 65:451-5. [PubMed: 3982720]

6. Brent RL. Bendectin: review of the medical literature of a comprehensively studied human nonteratogen and the most prevalent tortogen-litigen. Reprod Toxicol. Jul-Aug;1995 9(4):337-49. [PubMed: 7496090]

7. Centers for Disease Control and Prevention. Evaluation of an association between loratadine and hypospadias -- United States, 1997-2201. MMWR. 2004; 53:219-21. [PubMed: 15029117]

8. Diav-Citrin O, Shechtman S, Aharonovich A, Moerman L, Arnon J, Wajnberg R, et al. Pregnancy outcome after gestational exposure to loratadine or antihistamines: a prospective controlled cohort study. J Allergy Clin Immunol. Jun. 2003; 111(6):1239-43. [PubMed: 12789223]

9. Einarson A, Bailey B, Jung G, Spizzirri D, Baillie M, Koren G. Prospective controlled study of hydroxyzine and cetirizine in pregnancy. Ann Allergy Asthma Immunol. 1997; 78(2):183-6. [PubMed: 9048526]

10. Kallen B, Olausson PO. No increased risk of infant hypospadias after maternal use of loratadine in early pregnancy. Int J Med Sci. 2006; 3(3):106-7. [PubMed: 16761079]

11. McKeique PM, Lamm SH, Linn S, Kutcher JS. Bendectin and birth defects: I. A meta-analysis of the epidemiologic studies. Teratology. Jul. 1994; 50(1):27-37. [PubMed: 7974252]

12. McIntyre BS, Vancutsem PM, Treinen KA, Morrissey RE. Effects of perinatal loratadine exposure on male rat reproductive organ development. Reprod Toxicol. 2003; 17(6):691-7. [PubMed: 14613821]

13. Moretti ME, Caprara D, Coutinho CJ, Bar-Oz B, Berkovitch M, Addis A, et al. Fetal safety of loratadine use in the first trimester of pregnancy: a multicenter study. J Allergy Clin Immunol. 2003; 111(3):479-83. [PubMed: 12642825]

14. Nelson MM, Forfar JO. Associations between drugs administered during pregnancy and congenital abnormalities of the fetus. Br Med J. 1971; 1(5748):523-7. [PubMed: 4396080]

15. Paulus W, Schloemp S, Sterzik K, Stoz F. Pregnancy outcome after exposure to cetirizine/ levocetirizine in the first trimester-a prospective controlled study. Reprod Toxicol. 2004; 19:258. [Abstract].

16. Pedersen L, Nørgaard M, Skriver MV, Olsen J, Sørensen HT. Prenatal exposure to loratadine in children with hypospadias: a nested case-control study within the Danish National Birth Cohort. Am J Ther. Jul-Aug;2006 13(4):320-4. [PubMed: 16858167]

17. Schardein JL, Hentz DL, Petrere JA, Kurtz SM. Teratogenesis studies with diphenhydramine HCl. Toxicol Appl Pharmacol. Apr. 1971; 18(4):971-6. [PubMed: 5570246]

18. Schatz M, Petitti D. Antihistamines and pregnancy. Ann Allergy Asthma Immunol. 1997; 78(2): 157-9. [PubMed: 9048523]

19. Schwarz EB, Moretti ME, Nayak S, Koren G. Risk of hypospadias in offspring of women using loratadine during pregnancy: a systematic review and meta-analysis. Drug Saf. 2008; 31(9):77588. [PubMed: 18707192]

20. Seto A, Einarson T, Koren G. Pregnancy outcome following first trimester exposure to antihistamines: meta-analysis. Am J Perinatol. Mar. 1997; 14(3):119-24. [PubMed: 9259911]

21. Shaw GM, Todoroff K, Velie EM, Lammer EJ. Maternal illness, including fever and medication use as risk factors for neural tube defects. Teratology. Jan. 1998; 57(1):1-7. [PubMed: 9516745] 
22. Weber-Schoendorfer C, Schaefer C. The safety of cetirizine during pregnancy. A prospective observational cohort study. Reprod Toxicol. Sep. 2008; 26(1):19-23. [PubMed: 18571373]

23. Werler MM, Sheehan J, Mitchell AA. Maternal medication use and risk of gastroschisis and small intestinal atresia. Am J Epidemiol. 2002; 155:26-31. [PubMed: 11772781]

24. Wilton LV, Pearce GL, Martin RM, Mackay FJ, Mann RD. The outcomes of pregnancy in women exposed to newly marketed drugs in general practice in England. Br J Obstet Gynaecol. 1998; 105(8):882-9. [PubMed: 9746382]

25. Saxen I. Cleft palate and maternal diphenhydramine intake. Lancet. 1974; 1:407-8. [PubMed: 4131054]

26. Gilboa SM, Strickland MJ, Olshan AF, Werler MM, Correa A, National Birth Defects Prevention Study. Use of antihistamine medications during early pregnancy and isolated major malformations. Birth Defects Res A Clin Mol Teratol. Feb. 2009; 85(2):137-50. [PubMed: 19161158]

27. Kallen B, Olausson PO. Monitoring of maternal drug use and infant congenital malformations. Does loratadine cause hypospadias? Int J Risk Saf Med. 2001; 14:115-9.

28. Kallen B. Use of antihistamine drugs in early pregnancy and delivery outcome. J Matern Fetal Neonatal Med. 2002; 11:146-52. [PubMed: 12380668]

29. Heinonen, OP.; Slone, D.; Shapiro, S. Birth Defects and drugs in pregnancy. Publishing Sciences Group; Littleton, Massachusetts: 1977.

30. Golding J, Vivian S, Baldwin J. Maternal anti-nauseants and clefts of lip and palate. Hum Toxicol. Jan. 1983; 2(1):63-73. [PubMed: 6840794]

31. Aselton P, Jick H, Chentow SJ, Perera DR, Hunter JR, Rothman KJ. Pyloric stenosis and maternal Bendectin exposure. Am J Epidemiol. Aug; 1984 120(2):251-6. [PubMed: 6465123]

32. Eskenazi B, Bracken MB. Bendectin (Debendox) as a risk factor for pyloric stenosis. Am J Obstet Gynecol. Dec 15. 1982; 144(8):919-24. [PubMed: 7148924]

33. Mitchell AA, Rosenberg L, Shapiro S, Slone D. Birth defects related to bendectin use in pregnancy. I. Oral clefts and cardiac defects. JAMA. Jun 12; 1981 245(22):2311-4. [PubMed: 7230459]

34. Werler MM, Shapiro S, Mitchell AA. Periconceptional folic acid exposure and risk of occurrent neural tube defects. JAMA. 1993; 269(10):1257-1261. [PubMed: 8437302]

35. Louik C, Lin AE, Werler MM, Hernandez-Diaz S, Mitchell AA. First-trimester use of selective serotonin-reuptake inhibitors and the risk of birth defects. N Engl J Med. 2007; 356(26):26752683. [PubMed: 17596601]

36. Lin KJ, Mitchell AA, Yau WP, Louik C, Hernández-Díaz S. Safety of macrolides during pregnancy. Am J Obstet Gynecol. Dec 16.2012 doi: 10.1016/j.ajog.2012.12.023.

37. Yau WP, Lin KJ, Werler MM, Louik C, Mitchell AA, Hernandez-Diaz. Drug certainty-response in interview-based studies. Pharmacoepidemiol Drug Saf. Nov. 2011; 20(11):1210-6. [PubMed: 21913281]

38. Ludbrook J. Multiple comparison procedures updated. Clin Exp Pharmacol Physiol. Dec. 1998; 25(12):1032-7. [PubMed: 9888002]

39. Benjamini Y, Hochberg Y. Controlling the false discovery rate: a practical and powerful approach to multiple testing. J R Stat Soc. 1995; 57(1):289-300.Series B

40. Neutel CI, Johansen HL. Measuring drug effectiveness by default: the case of Bendectin. Can J Public Health. Jan-Feb;1995 86(1):66-70. [PubMed: 7728721]

41. Mitchell AA, Schwingl PJ, Rosenberg L, Louik C, Shapiro S. Birth defects in relation to Bendectin use in pregnancy. II. Pyloric stenosis. Am J Obstet Gynecol. Dec 1; 1983 147(7):737-42. [PubMed: 6650593]

42. Sheffield LJ, Batagol R. The creation of therapeutic orphans-or, what have we learnt from the Debendox fiasco? Med J Aust. Aug. 1985; 143(4):143-7. [PubMed: 3927122]

43. Press Announcement: "FDA approves Diclegis for pregnant women experiencing nausea and vomiting", April 8, 2013. http://www.fda.gov/NewsEvents/Newsroom/PressAnnouncements/ ucm347087.htm 
44. Werler MM, Pober BR, Nelson K, Holmes L. Reporting accuracy among mothers of malformed and nonmalformed infants. Am J Epidemiol. 1989; 129(2):415-21. [PubMed: 2643303]

45. Mitchell, AA. Special considerations in studies of drug-induced birth defects.. In: Strom, BL., editor. Pharmacoepidemiology. Third ed.. John Wiley \& Sons; NY: 2000. p. 750-63.

46. Khoury MJ, Erickson JD, James LM. Etiologic heterogeneity of neural tube defects: clues from epidemiology. Am J Epidemiol. Apr. 1982; 115(4):538-48. [PubMed: 7041633]

47. Bisceglia M, Galliani CA, Senger C, Stallone C, Sessa A. Renal cystic diseases: a review. Adv Anat Pathol. Jan. 2006; 13(1):26-56. [PubMed: 16462154] 


\section{Highlights box}

- Antihistamines are generally considered safe with respect to fetal risk. However, several studies have reported associations between specific antihistamines in early pregnancy and certain specific birth defects.

Findings from this study do not provide meaningful support for any strong associations between specific common antihistamines and specific major birth defects.

This study provides reassurance that commonly-used antihistamine medications appear to be relatively safe for women to take during pregnancy in terms of teratogenicity. 


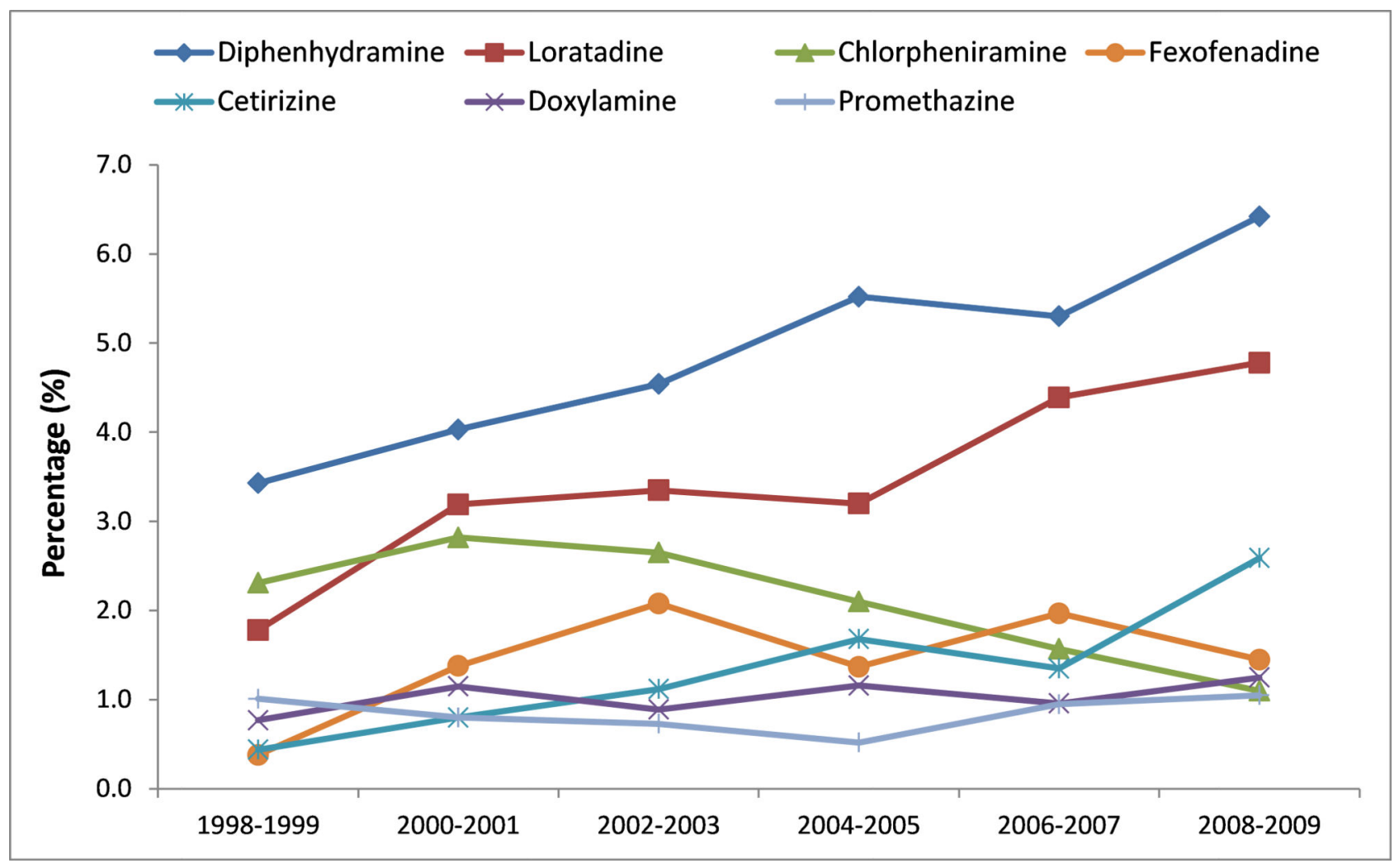

Figure 1.

Temporal Trend of First Trimester Antihistamine Use, Slone Epidemiology Center Birth Defect Study (BDS), 1998-2009

Based on data only from Boston and Philadelphia which have been participating in the BDS thoughout the study period; at the time of data extraction for this study, there were too few subjects interviewed in 2010 to include in this figure. 


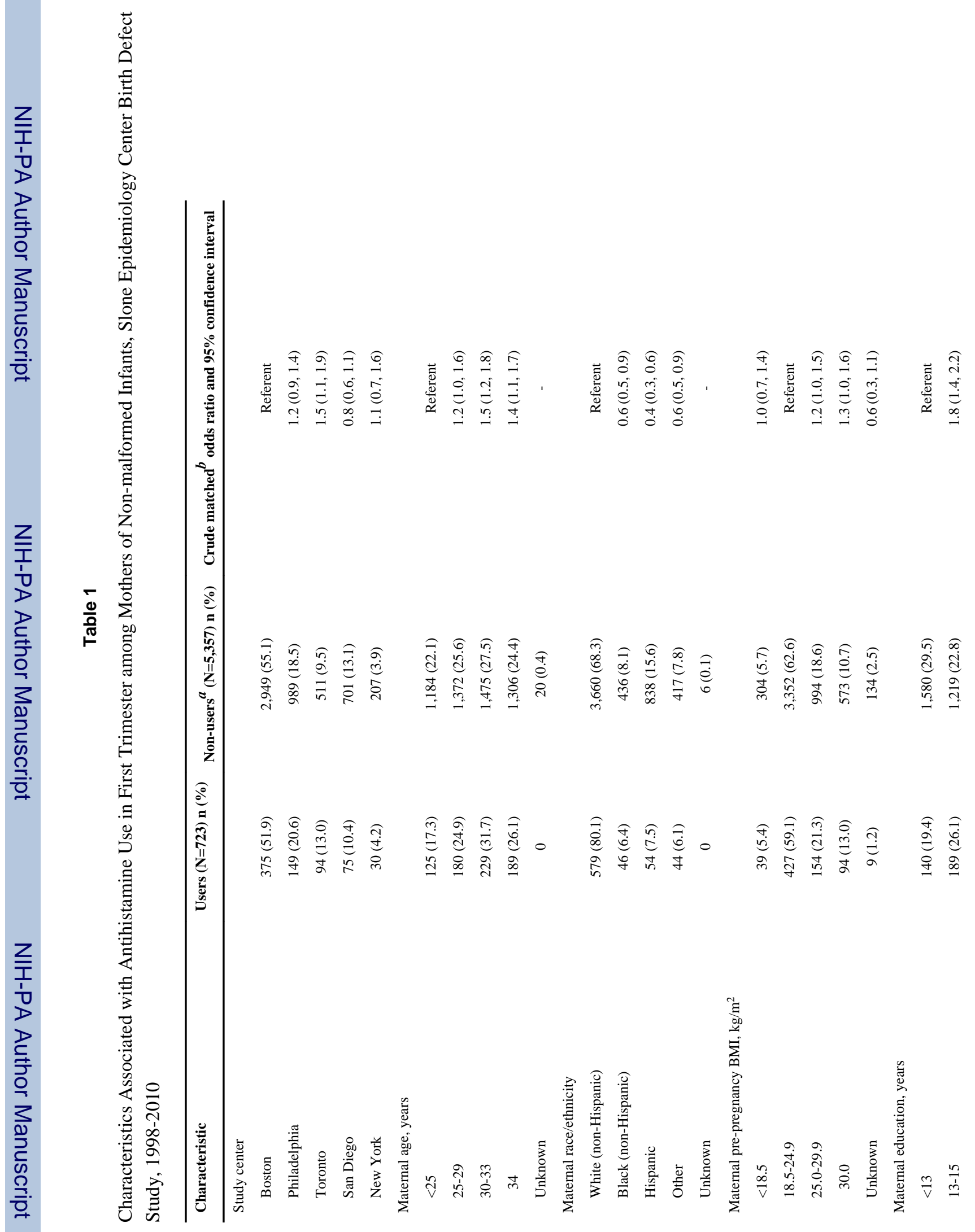




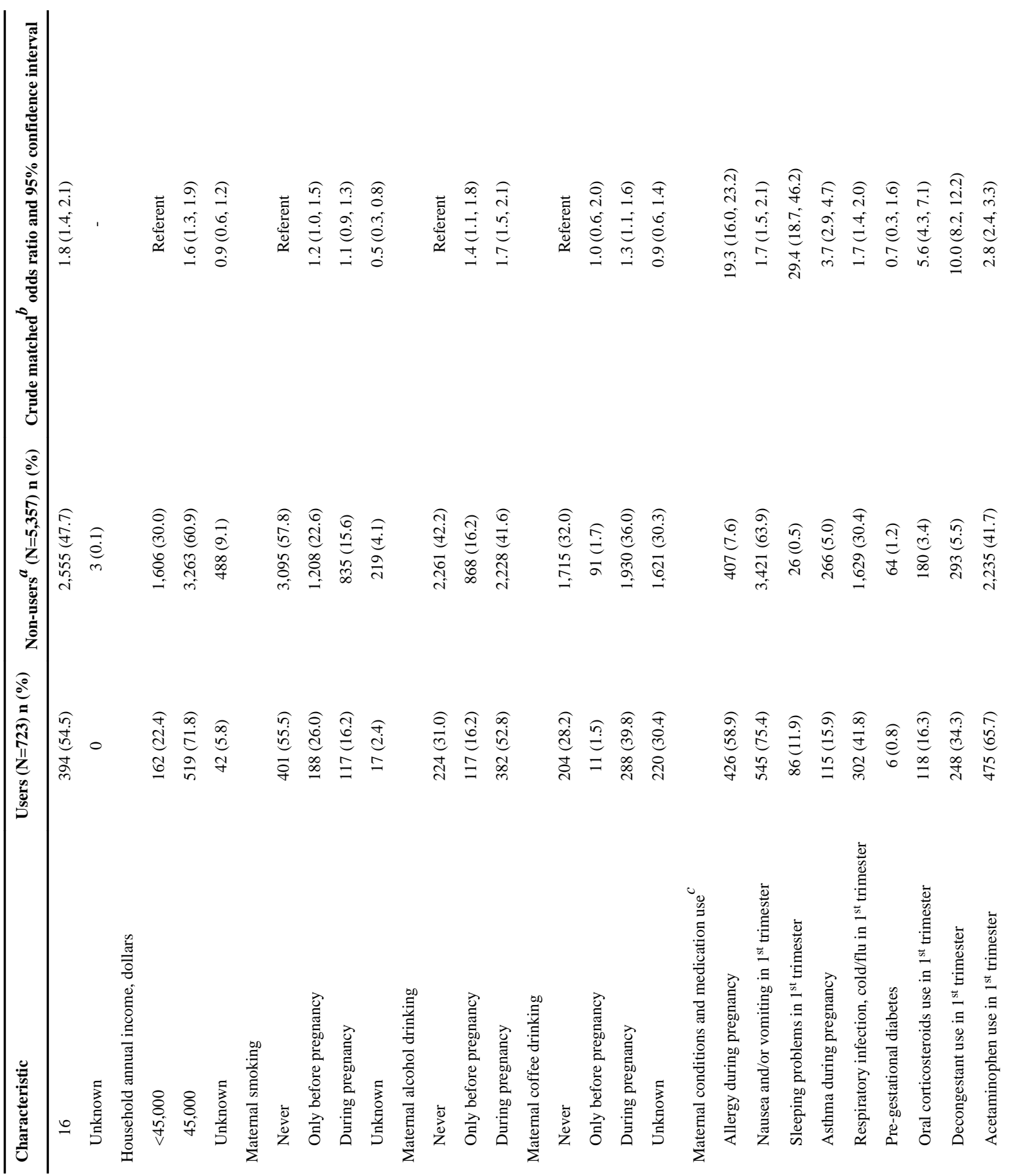




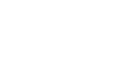

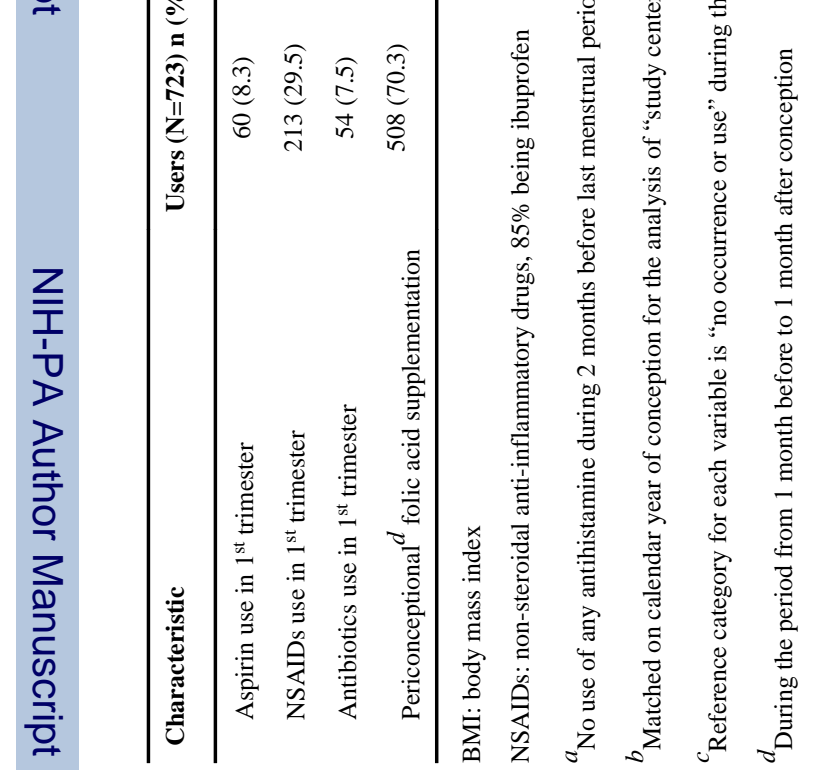




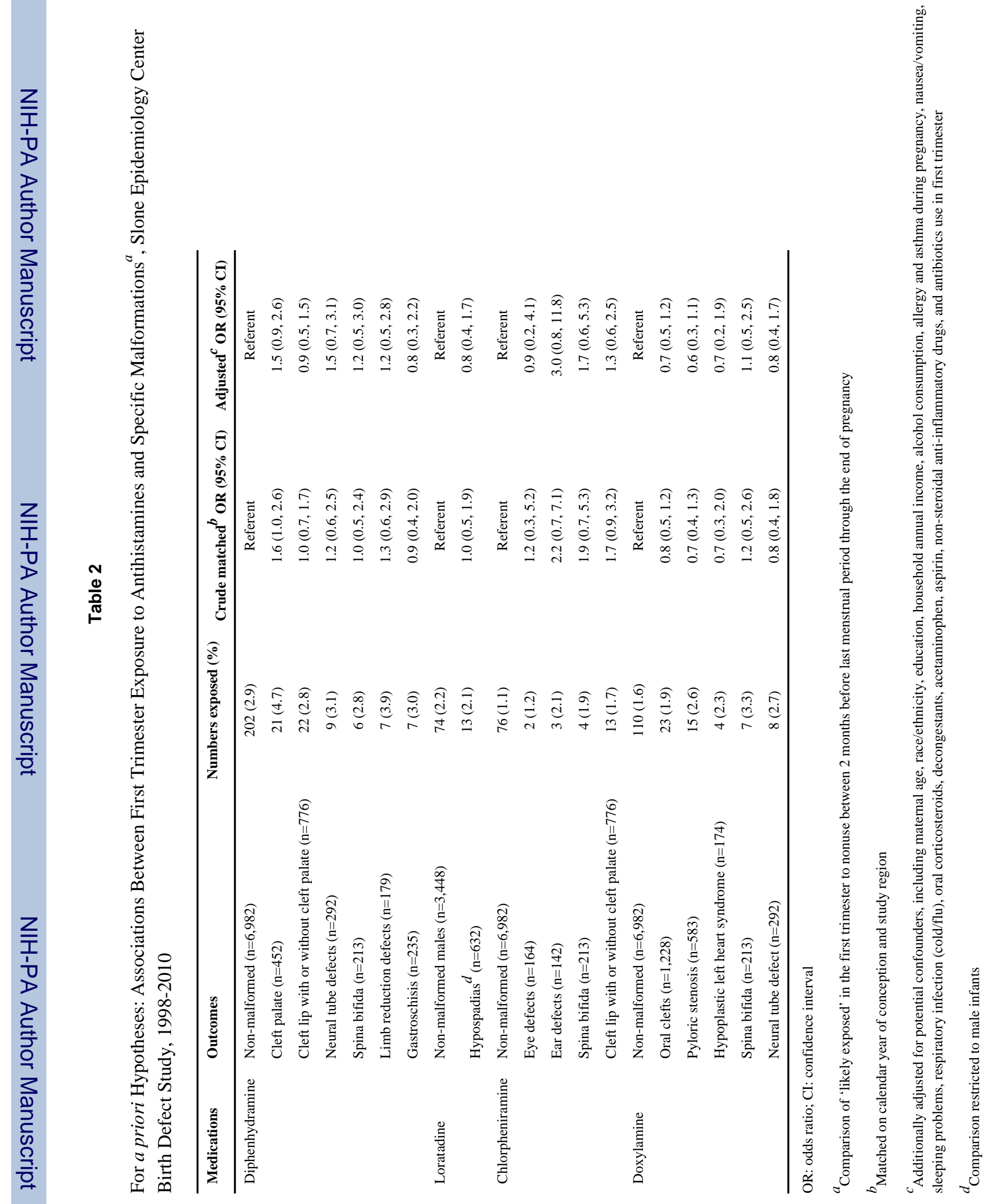




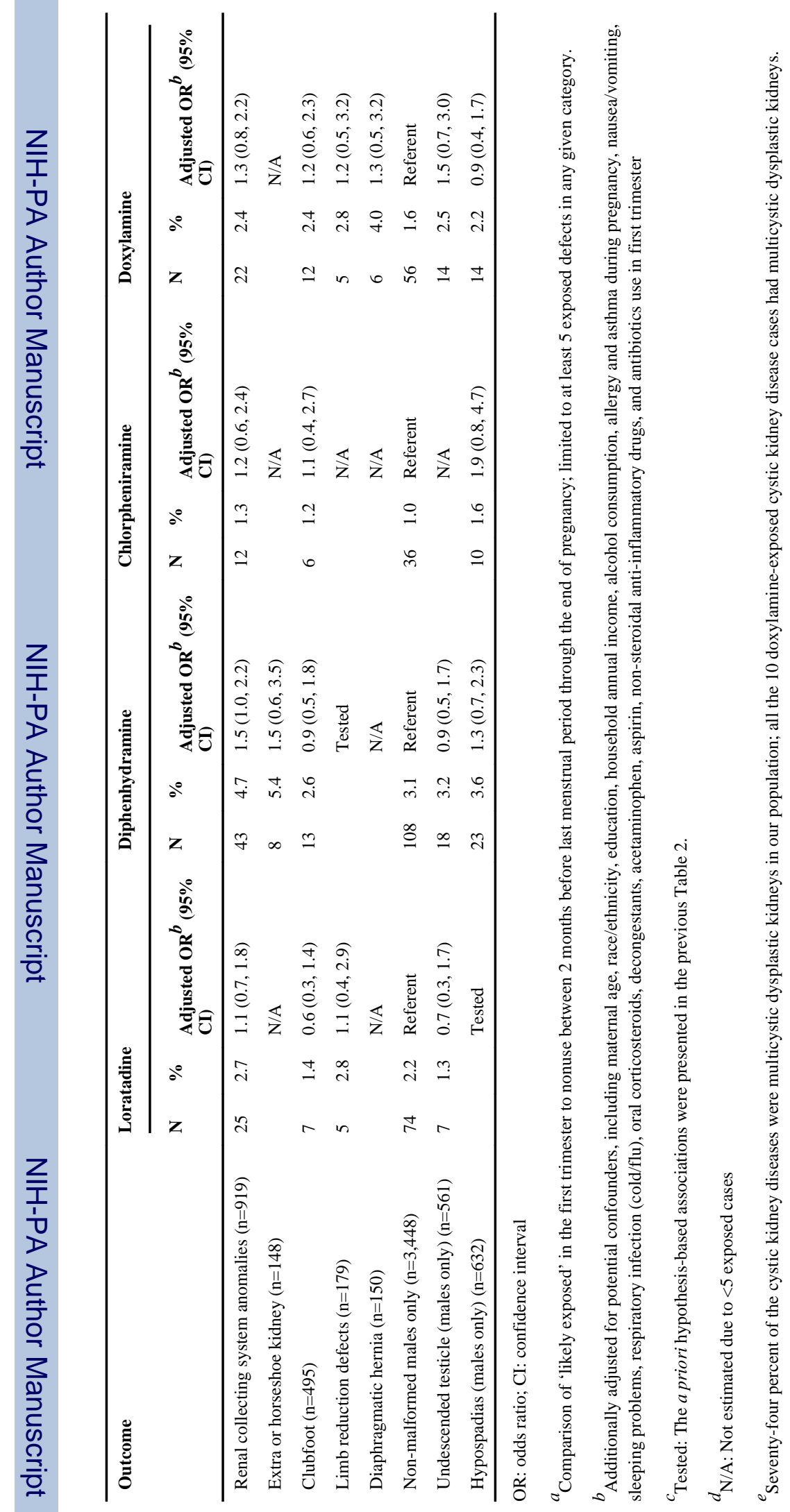

